\title{
Thermal Plasticity in the Burst Swimming of Bufo bankorensis Larvae
}

\author{
Jian-Jhih Lai ${ }^{1}$, Ping-Chun Lucy Hou ${ }^{1}$ and Yosef Steinberger ${ }^{2, *}$ \\ ${ }^{1}$ Institute of Biology, National Cheng Kung University, Tainan \\ ${ }^{2}$ The Mina \& Everard Goodman Faculty of Life Sciences, Bar-Ilan University, \\ Ramat Gan 5290002, Israel \\ Email: yosef.steinberger@biu.ac.il
}

This manuscript is dedicated to the memory of Prof. Ping-Chun Lucy Hou

\begin{abstract}
The Taiwanese toad Bufo bankorensis, found over a wide temperature and altitudinal range, can affect burst swimming performance and thermal acclimation ability. We studied (1) whether thermal acclimation affects larval burst swimming; and (2) whether altitudinal-population larvae differ in the thermal sensitivity of their burst swimming. Burst swimming performance was measured to obtain maximum velocity $\left(\mathrm{U}_{\max }\right)$, acceleration $\left(\mathrm{A}_{\max }\right)$, and distance moved within the initial 200 milliseconds $(\mathrm{ms})\left(\mathrm{D}_{200}\right)$. The length-adjusted $\mathrm{U}_{\max }$ of highland larvae acclimated at $22^{\circ} \mathrm{C}$ was significantly higher than that at $15^{\circ} \mathrm{C}$ when tested at 27 and $32^{\circ} \mathrm{C} . \mathrm{Q}_{10}$ for $\mathrm{U}_{\max }$ in the warmacclimated highland larvae was significantly higher than that in cool-acclimated larvae. All three locomotor parameters in both acclimation groups differed between altitudinal populations at $12-27^{\circ} \mathrm{C}$. $\mathrm{Q}_{10}$ for $\mathrm{U}_{\max }$ in the cool-acclimated highland larvae was lower than that in lowland larvae acclimated at same temperature. This indicates that the animal's acclimation ability is associated with seasonal temperature changes.
\end{abstract}

Keywords: Ectothermic vertebrate, Thermal sensitivity, Bufo bankorensis larva, Ecophysiological adaptation, Seasonality.

\section{$1 \quad$ Introduction}

Ectotherms, especially poikilotherms, can be susceptible to fluctuations in body temperature on a daily, as well as seasonal, basis [1]. Habitat alteration is known to be one of the most significant triggers in ecophysiological adaptation in ectotherms in a climate change era [2]. Changes in body temperature can affect many biological and physiological reactions of organisms and raise many ecophysiological adaptation struggles, through their effect on locomotion, foraging, and mating [3-5].

Bennett [1] demonstrated that locomotor performance is highly sensitive to change in body temperature, typically peaking at an optimal temperature and decreasing above and below this temperature. A decrease in locomotor performance was found to affect the ability of ectotherms to elude predators and capture prey [6,7]. Whole-animal performance traits, such as take-off velocity and jump distance, which are exposed to direct selection, will have ecological significance among different populations [8].

Several interspecific comparative studies [9-11] indicated that ectotherms from different thermal environments show variations in the thermal sensitivity of locomotor performance. John-Alder et al. [10] showed that several frog species in North America belonging to Hylidae, which inhabit or breed in a cooler environment, exhibited relatively better locomotor performance at low temperatures than species from a warmer environment. Navas [11] showed that the locomotor performance of neotropical anurans from the Colombian Andes, living at a high-elevation (above $2900 \mathrm{~m}$ ), exhibited low thermal sensitivity at a temperature range of $5-35^{\circ} \mathrm{C}$ compared with the performance of the low-altitude species, which were substantially balanced at temperatures below $15^{\circ} \mathrm{C}$.

Some studies that compared specific populations of amphibian and reptilian species found very little 
variations in thermal sensitivity of locomotor performance [12, 13]. However, Wilson [8] investigated the thermal sensitivity of jumping performance among Limnodynastes peronii populations in Australia, and demonstrated that the cool-environment populations consistently performed better at lower temperatures than that inhabited the warmer climate, and vice versa at higher temperatures.

Some ectotherms can adjust their locomotor performance when exposed to a thermal environment for an extended period of time (thermal acclimation) [7, 14-16]. Several fish species change maximum speed of burst swimming during thermal acclimation [14, 17-19]. Adult amphibians living in aquatic (Xenopus laevis) [20] or semi-aquatic (salamanders) [21, 22] environments exhibited thermal acclimation ability in their locomotor performance. However, the locomotor performances of metamorphosed amphibians living in terrestrial habitats were found to be insensitive to thermal acclimation [23-27].

Wilson and Franklin [27] found that the capacity for thermal acclimation in locomotor performance existed in the larval stage but not in the adult stage of Limnodynastes peronii. They used a hypothetical scenario to show the relationship between variations in body temperature daily or seasonally, and the evolution of both the thermal sensitivity and thermal acclimation of performance in ectotherms. Living in an aquatic environment, where very moderate changes are followed by a small variation in body temperature, could be the cause of a selection result to thermal sensitivity of performance. This would be on the premise of seasonal variations in environmental temperature.

Field observations showed that the breeding season of B. bankorensis in the lowland (Nanjenshan, 300 $\mathrm{m})$ is from late August to November, and the larval period lasts for less than two months. It is a relatively stable thermal environment $\left(18-25^{\circ} \mathrm{C}\right)$ compared with that of the highland population (Alishan, $2300 \mathrm{~m}$ ), which breeds year round, and the larvae may overwinter before metamorphosis. The $B$. bankorensis larvae in the highland environment might experience seasonal temperature changes ranging from $7^{\circ} \mathrm{C}$ to $20^{\circ} \mathrm{C}$.

Based on the above field observations, we hypothesized that larvae collected from the highland will have low thermal sensitivity and advanced thermal acclimation capacity in their burst swimming performance because of the thermal-buffered aquatic environment and seasonal changes of water temperature in the highland. Comparing the burst swimming performance of B. bankorensis larvae with other populations, we hypothesized that larvae collected at the highland from the cool environment (season) will perform improved burst swimming at low temperature compared with that collected from the lowland - warm environment (season), and vice versa at high temperature.

\section{Materials and Methods}

B. bankorensis is an endemic species found in Taiwan and is widely distributed from the lowland to an elevation of above $3000 \mathrm{~m}$ [28]. It is, therefore, exposed to a different temperature history according to different habitats, as determined by altitudinal location.

\subsection{Study Site}

B. bankorensis larvae were collected from two extreme habitats: a lowland site located at the Guhu Lake $\left(20^{\circ} 05^{\prime} \mathrm{N}, 120^{\circ} 51^{\prime} \mathrm{E}\right.$; altitude $\left.300 \mathrm{~m}\right)$, and a site located at the Elder Sister Lake $\left(23^{\circ} 30^{\prime} \mathrm{N}, 1^{\circ} 0^{\circ} 48^{\prime} \mathrm{E}\right.$; altitude $2300 \mathrm{~m}$ ). The Guhu Lake is located in the Nanjenshan Nature Reserve, Kenting National Park. According to measurements conducted by Chang [29] between March and December 2001, the maximal and minimal upper $(10 \mathrm{~cm})$ water layer temperatures recorded were $34.8^{\circ} \mathrm{C}$ and $12.1^{\circ} \mathrm{C}$, respectively. Based on field observations (Jian-Jhih Lai, personal observation), the B. bankorensis breeding season at this site takes place only in the period between late August and November, since adult 'specimens' were found only in November.

The second study site is located at the Elder Sister Lake (233' N, $120^{\circ} 48^{\prime} \mathrm{E}$; altitude $\left.2300 \mathrm{~m}\right)$ in Alishan, Chiayi County, in the center of Taiwan. The highest and lowest temperatures recorded by Chang [29] at the $10 \mathrm{~cm}$ upper water layer from May 2001 to February 2002 were $21.62^{\circ} \mathrm{C}$ and $7.14^{\circ} \mathrm{C}$, respectively. B. bankorensis larvae can be found at this site all year round.

\section{$2.2 \quad$ B. bankorensis Larval Collection}


Random larval specimens of B. bankorensis, ranging from 100 to 150 individuals each specimen, were collected from each study site in the winter season, i.e., October 2003. A larval population, as described above, was also collected from the Elder Sister Lake in the summer season (May 2004) in order to compare two breeding seasonalities.

The B. bankorensis larval population was collected using a mesh net in order to minimize body damage, and placed in a container with 2 liters of water for transport to the laboratory, located at National Cheng-Kung University in Tainan City. Only young, hatched larvae (tadpoles) were used for the laboratory burst swimming experiments. All samples were returned to the original sites at the end of the study period.

\subsection{Acclimation and Experimental Protocol}

Following each collection, B. bankorensis larvae were transported to the laboratory and randomly divided into two groups for acclimation at 15 and $22^{\circ} \mathrm{C}$. During the 28-day acclimation period, $B$. bankorensis larvae from each of these two groups were maintained in tanks with aerated water. Each group contained 16 larvae $\mathrm{L}^{-1}$ and was placed in a temperature-controlled refrigerator set to an acclimation temperature of $12 \mathrm{~h} \mathrm{L:12} \mathrm{h} \mathrm{D} \mathrm{photoperiod} \mathrm{cycles.} \mathrm{In} \mathrm{such} \mathrm{an} \mathrm{environment,} \mathrm{the} \mathrm{larval} \mathrm{stage}$ will have slower growth and developmental rates [30]. The water in the acclimation tanks was replaced with fresh and aerated water every other day. The larvae were fed with $50 \mathrm{mg}$ fish pellets every other day (based on the remaining pellets) every time the water was changed.

At the end of the 28-day acclimation period, ten larvae at Gosner stages 25-38 (legs absent), with body shape and swimming dynamics as described by Steuhower and Farel [31] and Wilson and Franklin [32], were randomly selected from each acclimated group for the measurement of swimming performance.

Burst swimming of the larvae was performed in an arena that was divided into a test area $\left(28.5^{*} 28.5 * 6.5 \mathrm{~cm}^{3}\right)$ and a waiting area (composed of 20 cells, $\left.2.3^{*} 2.6 * 6.5 \mathrm{~cm}^{3}\right)$. The arena was submerged in a circulating water tank connected to a temperature-controlled water bath. The water level in the arena test area was only $1 \mathrm{~cm}$ deep in order to avoid too much vertical larval movement. Each individual larva was tested at six different temperatures by the following randomly selected predetermined sequence of $22,12,32,17,27$, and $22^{\circ} \mathrm{C}$. An additional test at a temperature of $22^{\circ} \mathrm{C}$ was used as a repeated measurement in order to evaluate the change in larval performance compared to the initial results $\left(22^{\circ} \mathrm{C}\right)$. All measurements were performed on three successive days between 9:00 and 15:00 in order to avoid the diel effect. The performance test was carried out only when the water temperature reached the experimental temperature of $22^{\circ} \mathrm{C}$, used as a reference temperature. Each larva was replaced in its individual arena during adjustment to the new water temperature. The water temperature adjustment was performed under a control rate of $6^{\circ} \mathrm{C} \mathrm{h}^{-1}$, allowing the larva to become acclimated to the new environment. At each temperature, 20 larvae in the waiting area were randomly selected and placed in the test site for the burst swimming test. The larva was left to become accustomed to the surroundings for one minute, after which the base of its tail was gently tapped with a fine steel wire (less than $1 \mathrm{~mm}$ ), inducing a startle touchiness. Ten startle responses were induced in each individual larva at each test temperature. All burst larval swimming was photographed from a stationary time zero at a rate of 50 frames $\mathrm{s}^{-1}$ with a CCD camera (JAI CV-M40) suspended vertically above the swimming arena. The photographed images were digitized at the same rate by a frame grabber (Matrox Meteor II Multichannel, Meteor II-MC PCI board), and then saved as video files compressed with Matrox MIL Codec 4.0.0.1. The process of image acquisition was done using Inspector 4.1 software (Matrox Electronic System Ltd., Quebec, Canada). At the end of data collection, the total length of each individual larva was determined using Inspector 4.1 and a photograph taken by a digital camera (Nikon CoolPix 5000). At the closing stages of each day, the larvae were placed in individual cups and returned to the incubator at their acclimation temperatures for further burst swimming tests.

\subsection{Determination of Burst Swimming Parameters}

The coordinates of the center point of a larva's head in successful swimming sequences, which were defined as the trials in which the larva did not knock against the arena wall during the initial 200 millisecond (ms) period of burst swimming, were automatically determined using the pattern-matching function of Inspector 4.1. The raw displacement vectors were calculated from the raw position and then 
smoothed by a digital filter according to Winter's [33] equation. An automatic optimization of the cutoff frequency was applied using the Cappello et al. [34] and Challis [35] technique before calculation of the velocity and acceleration. The smoothed displacement and velocity vectors were differentiated by three-point central difference approximation to obtain velocity and acceleration (Gerald and Wheatley, [36]). Maximal velocity $\left(\mathrm{U}_{\max }\right)$, maximal acceleration $\left(\mathrm{A}_{\max }\right)$, and total distance moved within the initial $200 \mathrm{~ms}$ of swimming $\left(\mathrm{D}_{200}\right)$, were determined for each individual larva at each test temperature. All calculations were performed in Microsoft Excel and all results are presented as means $( \pm \mathrm{SE})$.

\subsection{Statistical Analysis}

A three-way analysis of covariance (ANCOVA) was performed to examine the differences between altitudes, seasons, and acclimation temperatures at each test temperature, with total body length as the covariate. The adjusted locomotor parameters were used to calculate the least square and $\mathrm{Q}_{10}$ in view of the fact that body length might affect swimming performance [32]. The least square method was used to test the equality of means of specific treatment groups. $\mathrm{Q}_{10}$ values over the test temperatures of $12-32^{\circ} \mathrm{C}$ for the three locomotor parameters were analyzed with a three-way analysis of variance (ANOVA) to examine the effects of altitude, season, and acclimation temperature. The specific differences between treatments were analyzed by $t$-tests. Body length and the developmental stages of larvae in different acclimation groups were compared using the $t$-test and Mann-Whitney $U$ test, respectively. The swimming parameters at $22^{\circ} \mathrm{C}$ measured at the beginning and end of the experiments were compared using a paired $t$-test. All statistical analyses were performed using the SAS program (v9.1, SAS Institute Inc.).

\section{$3 \quad$ Results}

Table 1. Mean values $( \pm \mathrm{SD})$ of total length $(\mathrm{mm})$ and development stage of Bufo bankorensis larvae collected at different altitudes after acclimation of 28 days at $15^{\circ} \mathrm{C}$ and $22^{\circ} \mathrm{C}$.

\begin{tabular}{|c|c|c|c|c|}
\hline \multirow[b]{3}{*}{ Altitude/Season } & \multicolumn{4}{|c|}{ Acclimation temperature } \\
\hline & \multicolumn{2}{|c|}{$15^{\circ} \mathrm{C}$} & \multicolumn{2}{|c|}{$22^{\circ} \mathrm{C}$} \\
\hline & Length $(\mathrm{mm})$ & Stage $^{a}$ & Length $(\mathrm{mm})$ & Stage $^{\mathrm{a}}$ \\
\hline Lowland & & & & \\
\hline $\begin{array}{l}\text { Winter } \\
\text { Highland }\end{array}$ & $28.8 \pm 0.47$ & $33.7(31-36)$ & $29.8 \pm 0.49$ & $37.0(35-38)^{* * *}$ \\
\hline Winter & $26.6 \pm 0.44$ & $28.2(25-31)$ & $28.1 \pm 0.24^{*}$ & $35.9(35-37)^{* * *}$ \\
\hline Summer & $25.3 \pm 0.71$ & $29.6(28-31)$ & $25.9 \pm 0.37$ & $33.4(30-35)^{* *}$ \\
\hline
\end{tabular}

${ }^{\mathrm{a}}$ Gosner [37]

The lowland and highland larvae were acclimated for 28 and 33 days, respectively.

Total length values are means $\pm \mathrm{SE}$, and developmental stages are shown as means (minimum stage-maximum stage).

One, two, and three asterisks denote a significant difference between acclimation groups at $\mathrm{p}<0.05,0.01$, and 0.001 , respectively.

B. bankorensis larvae collected from the two study sites, the lowland and the highland, during the winter period, were acclimated for 28 days at $15^{\circ} \mathrm{C}$ and $22^{\circ} \mathrm{C}$ before the burst swimming experiments. At the end of the acclimation period, the larval populations were measured at each acclimated temperature in order to define their developmental stage according to Gosner [37]. The results (Table 1) did not show any significant differences in the total body length of the larvae between the acclimated temperatures for the lowland site, whereas a significant $(\mathrm{p}<0.05)$ difference between the two thermal acclimated groups was observed at the highland site. Moreover, based on hind-leg-development observation, a significant difference $(\mathrm{p}<0.001)$ was found in the developmental stage between the two acclimation groups (Table 1 ).

No significant differences were found in the size of larvae collected during the summer period at the highland site and at the end of the 28 days of acclimation at the two above-mentioned temperatures. 
However, a pattern similar to that of the winter season collection was observed in the developmental stage (Table 1$)$, with significant differences $(\mathrm{p}<0.01)$.

\subsection{Burst Swimming Performance}

The burst swimming performance at $22^{\circ} \mathrm{C}$, measured at the end of the experiment, was better than that measured at the beginning of the experiment in both altitudinal larval groups (Table 2). For the lowland larvae acclimated at $15^{\circ} \mathrm{C}$, maximal acceleration $\left(\mathrm{A}_{\max }\right)$ and distance moved within $200 \mathrm{~ms}\left(\mathrm{D}_{200}\right)$ of burst swimming measured at the end of the experiment were $42 \%$ and $34 \%$, respectively, higher than those values found at the beginning of the experiment $(\mathrm{p}=0.0332$ and $\mathrm{p}=0.001$, respectively) (Table 2). For the lowland larvae acclimated at $22^{\circ} \mathrm{C}, \mathrm{D}_{200}$ measured at the end of experiment was $31 \%$ higher than at the beginning of the experiment $(\mathrm{p}=0.0253)$ (Table 2$)$.

Table 2. Mean $( \pm \mathrm{SD})$ differences in burst swimming parameters measured at the beginning $(\mathrm{B})$ and the end $(\mathrm{E})$ of experiments at $22^{\circ} \mathrm{C}$ in Bufo bankorensis larvae acclimated at 15 and $22^{\circ} \mathrm{C}$.

\begin{tabular}{|c|c|c|c|c|c|c|}
\hline \multirow{3}{*}{$\begin{array}{l}\text { Altitude } \\
\text { /Season }\end{array}$} & \multicolumn{6}{|c|}{ Acclimation temperature } \\
\hline & \multicolumn{2}{|c|}{$\mathrm{U}_{\max }(\mathrm{B}-\mathrm{E})\left(\mathrm{m} \mathrm{s}^{-1}\right)$} & \multicolumn{2}{|c|}{$\mathrm{A}_{\max }(\mathrm{B}-\mathrm{E})\left(\mathrm{m} \mathrm{s}^{-2}\right)$} & \multicolumn{2}{|c|}{$\mathrm{D} 200(\mathrm{~B}-\mathrm{E})(\mathrm{cm})$} \\
\hline & $15^{\circ} \mathrm{C}$ & $22^{\circ} \mathrm{C}$ & $15^{\circ} \mathrm{C}$ & $22^{\circ} \mathrm{C}$ & $15^{\circ} \mathrm{C}$ & $22^{\circ} \mathrm{C}$ \\
\hline \multicolumn{7}{|l|}{ Lowland } \\
\hline Winter & $-0.021 \pm 0.0166$ & $-0.015 \pm 0.0250$ & $-1.05 \pm 0.410^{*}$ & $-0.82 \pm 0.451$ & $-1.03 \pm 0.205^{* *}$ & $-0.83 \pm 0.312^{*}$ \\
\hline \multicolumn{7}{|c|}{ Highland } \\
\hline Winter & $-0.004 \pm 0.0128$ & $0.018 \pm 0.0102$ & $-0.40 \pm 0.205$ & $-0.33 \pm 0.277$ & $-0.28 \pm 0.172$ & $0.05 \pm 0.203$ \\
\hline Summer & $-0.010 \pm 0.0134$ & $-0.035 \pm 0.0097^{* *}$ & $-0.51 \pm 0.459$ & $-0.98 \pm 0.304^{*}$ & $-0.31 \pm 0.184$ & $-0.62 \pm 0.127^{* * *}$ \\
\hline
\end{tabular}

$\mathrm{U}_{\max }, \mathrm{A}_{\max }$, and $\mathrm{D}_{200}$ indicate maximum velocity, acceleration, and distance moved within the initial $200 \mathrm{~ms}$ of burst swimming, respectively.

Values are means $\pm \mathrm{SE}$.

One, two, or three asterisks denote a significant difference between the initial and last testing at $\mathrm{p}<0.05,0.01$, or 0.001 .

For the summer collection of larvae from the high altitude acclimated at $22^{\circ} \mathrm{C}, \mathrm{U}_{\max }, \mathrm{A}_{\max }$, and $\mathrm{D}_{200}$, results obtained at the end of the experiment were $13 \% \quad(p=0.0058), 29 \% \quad(p=0.0103)$, and $16 \%$ $(\mathrm{p}=0.0009)$, respectively, higher than in the initial test. For the winter and summer collection of larvae from the high altitude, acclimated at $15^{\circ} \mathrm{C}$, burst swimming performance at the launch of the experiment did not differ significantly from that at the end of the test (Table 2). Based on the obtained results, it appeared that repeated measurement might affect the burst swimming performance at $22^{\circ} \mathrm{C}$. Subsequent comparisons were, therefore, made using only the values measured at the beginning of the test at $22^{\circ} \mathrm{C}$.

The burst swimming velocity $\left(\mathrm{U}_{\max }\right)$, which was adjusted, calculated for the B. bankorensis larvae collected during the winter season, and acclimated at the two temperatures $\left(15\right.$ and $\left.22^{\circ} \mathrm{C}\right)$, is presented in Figure $1 \mathrm{~A}$ and B. A gradual increase in $\mathrm{U}_{\max }$ adjusted from a value of 0.16 and $0.21 \mathrm{~m} / \mathrm{s}$ to 0.31 and $0.29 \mathrm{~m} / \mathrm{s}$, was obtained for 12 and $32^{\circ} \mathrm{C}$ for lowland and highland populations, respectively.

The acclimated group at $15^{\circ} \mathrm{C}$ demonstrated a significant difference in burst swimming velocities $\left(U_{\max }\right)$ between highland and lowland larvae for 12 and $17^{\circ} \mathrm{C}$ (Fig. 1A), respectively. Furthermore, the $\mathrm{U}_{\max }$ of larvae acclimated at $22^{\circ} \mathrm{C}$ from the highland showed a significantly better performance at all temperatures except $15^{\circ} \mathrm{C}$ compared with larvae acclimated at the same temperature but collected from the lowland site (Fig. 1B).

There were significant differences in our study between the two acclimated groups in $\mathrm{U}_{\max }$ values only for larvae collected from the highland site (Fig. 1A) at higher temperatures $\left(17-32^{\circ} \mathrm{C}\right)$.

The burst swimming acceleration $\left(\mathrm{A}_{\max }\right)$ was calibrated and calculated based on the B. bankorensis larvae collected during the winter season acclimated at 15 and $22^{\circ} \mathrm{C}$ (Fig. $1 \mathrm{C}$ and D). Larvae collected from the highland exhibited a significantly $(\mathrm{p}<0.05)$ better performance in $\mathrm{A}_{\max }$ at all trial temperatures. A significant difference $(\mathrm{p}<0.05)$ in $\mathrm{A}_{\max }$ was obtained at $22^{\circ} \mathrm{C}$ in the $15^{\circ} \mathrm{C}$-acclimated group, and at 17 $27^{\circ} \mathrm{C}$ in the $22^{\circ} \mathrm{C}$ acclimated group, but no significant differences in $\mathrm{A}_{\max }$ were observed between the two acclimated groups $\left(15\right.$ and $\left.22^{\circ} \mathrm{C}\right)$ (Fig. $1 \mathrm{C}$ and $\left.\mathrm{D}\right)$. 

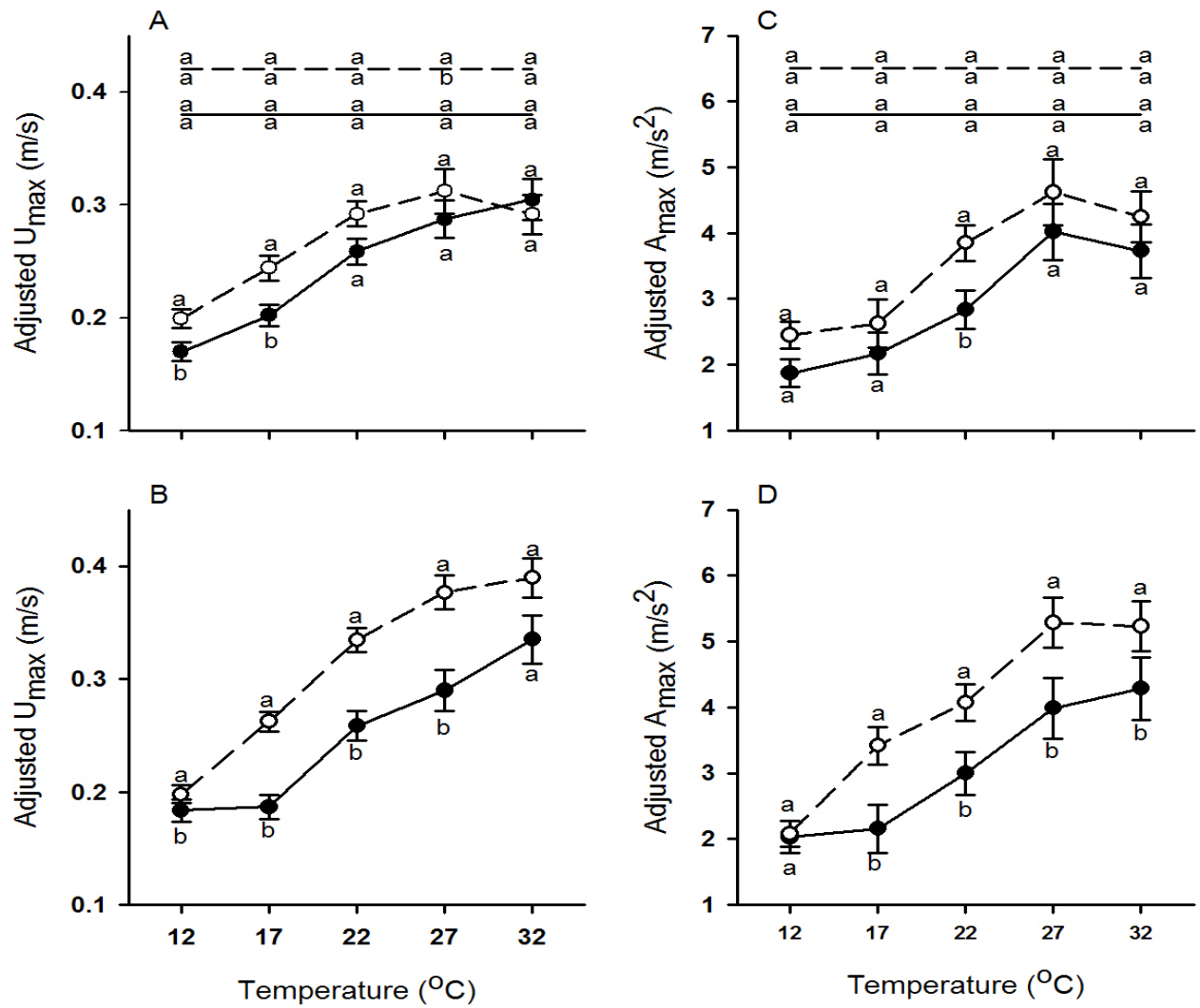

Figure 1. Maximal burst swimming velocities (Umax) and accelerations (Amax) performed at test temperatures of $12-32^{\circ} \mathrm{C}$ by Bufo bankorensis larvae acclimated at 15 and $22^{\circ} \mathrm{C}$ from Nanjenshan $(\bullet)$ and Alishan (o), respectively, in winter

The distances passed within $200 \mathrm{~ms}\left(\mathrm{D}_{200}\right)$ by larval burst swimming are presented in Figure $2 \mathrm{~A}$ and B. Larvae collected from the highland site generally performed better at $\mathrm{D}_{200}$ than larvae from the lowland site at all temperatures except $12^{\circ} \mathrm{C}$ for the $22^{\circ} \mathrm{C}$-acclimated larvae (Fig. 2A, B).

Thermal sensitivities of locomotor performance represented by $\mathrm{Q}_{10}$ values are presented in Figure $2 \mathrm{C}$ and D. Larvae from the highland expressed a lower sensitivity in $\mathrm{U}_{\max }(1.23 \pm 0.033)$ than larvae collected from the lowland (1.33 \pm 0.028$)$, although they acquired a higher sensitivity (1.41 \pm 0.046$)$ after acclimatization at $22^{\circ} \mathrm{C}$.

The burst swimming performances of larvae collected in winter and summer from the highland site are presented in Figures 3 and 4. Larvae collected in the winter season performed better in $\mathrm{U}_{\max }$ than larvae collected in summer at lower temperatures of 22,17 , and $12^{\circ} \mathrm{C}$ (Figs. 3A-D and 4A-B), although no significant differences $(\mathrm{p}=0.0728)$ were obtained at $17^{\circ} \mathrm{C}$ in the $15^{\circ} \mathrm{C}$-acclimated group. The burst swimming performance of larvae collected in the summer season at the highland site showed a better performance of $\mathrm{U}_{\max }$ at 27 and $32^{\circ} \mathrm{C}$, and a $\mathrm{D}_{200}$ at $27^{\circ} \mathrm{C}$ for larvae acclimated at $22^{\circ} \mathrm{C}$. The acclimation effect was found to show a similar trend to that of thermal sensitivity $\left(\mathrm{Q}_{10}\right.$ value) of $\mathrm{U}_{\max }$ between 12 and $32^{\circ} \mathrm{C}$ for the larvae collected in summer from the highland site (changed from $1.28 \pm 0.030$ to 1.45 $\pm 0.040)$ (Fig. 4D). 

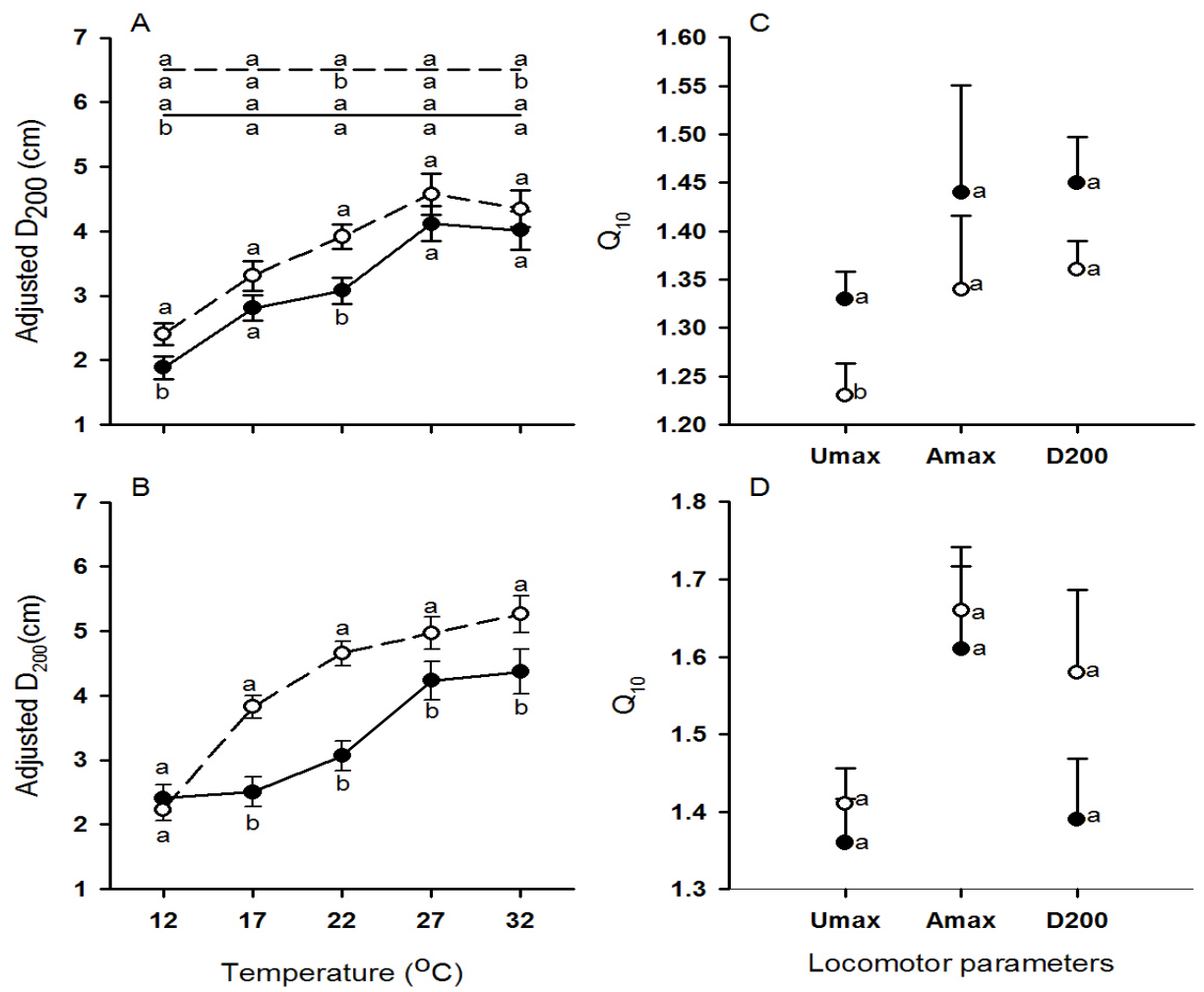

Figure 2. Distance moved within the initial $200 \mathrm{~ms}$ (D200) of burst swimming and thermal sensitivity, represented by a Q10 value of three locomotion performances that were performed at test temperatures of $12-32^{\circ} \mathrm{C}$ by $\mathrm{Bufo}$ bankorensis larvae acclimated at 15 and $22^{\circ} \mathrm{C}$ from Nanjenshan $(\mathbf{O})$ and Alishan $(\bigcirc)$, respectively, in winter.
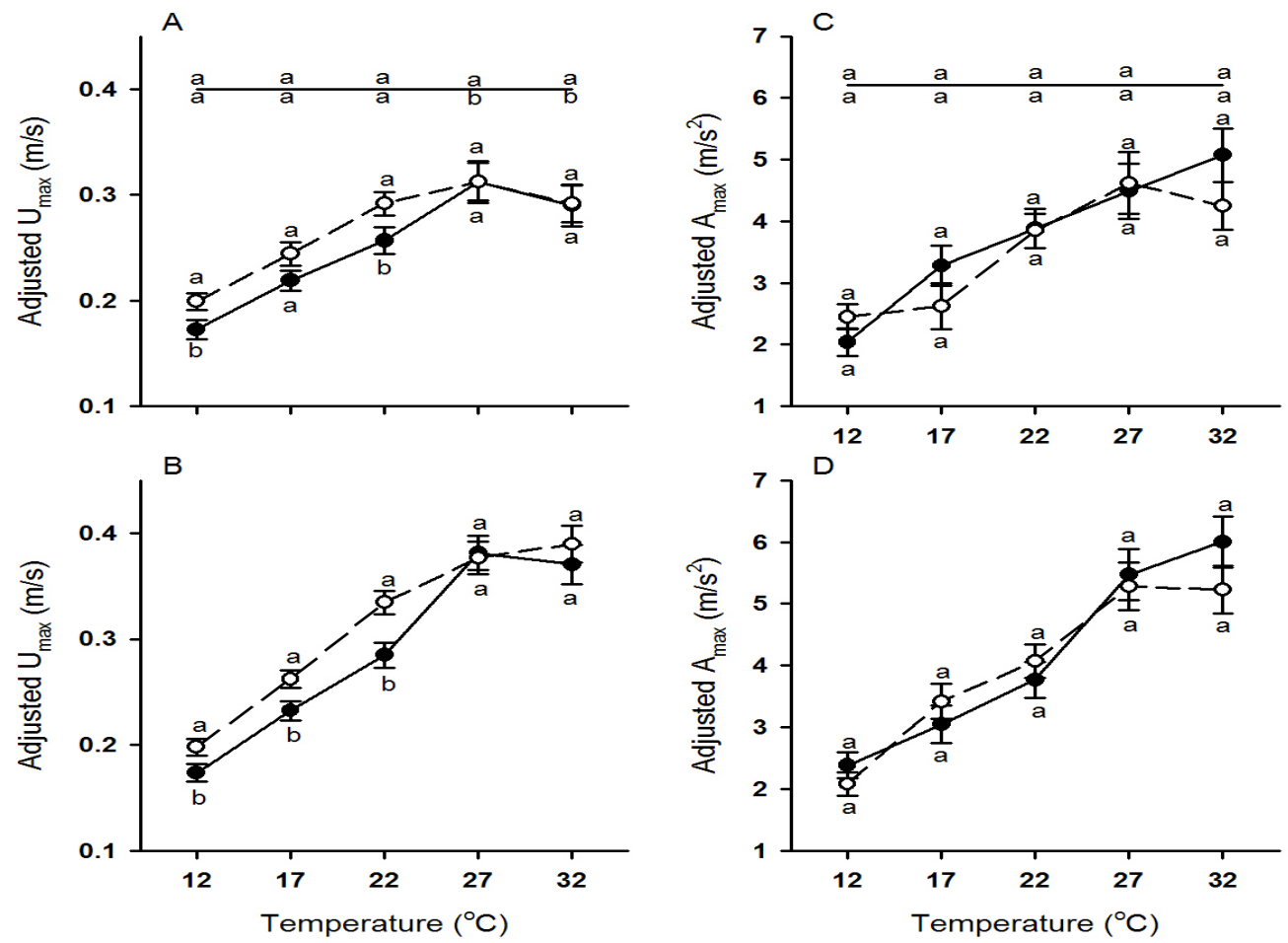

Figure 3. Maximal burst swimming velocities $\left(\mathrm{U}_{\max }\right)$ and accelerations $\left(\mathrm{A}_{\max }\right)$ performed at test temperatures of 12$32^{\circ} \mathrm{C}$ by Bufo bankorensis larvae acclimated at 15 and $22^{\circ} \mathrm{C}$ from Alishan in winter (o) and summer (•), respectively. 

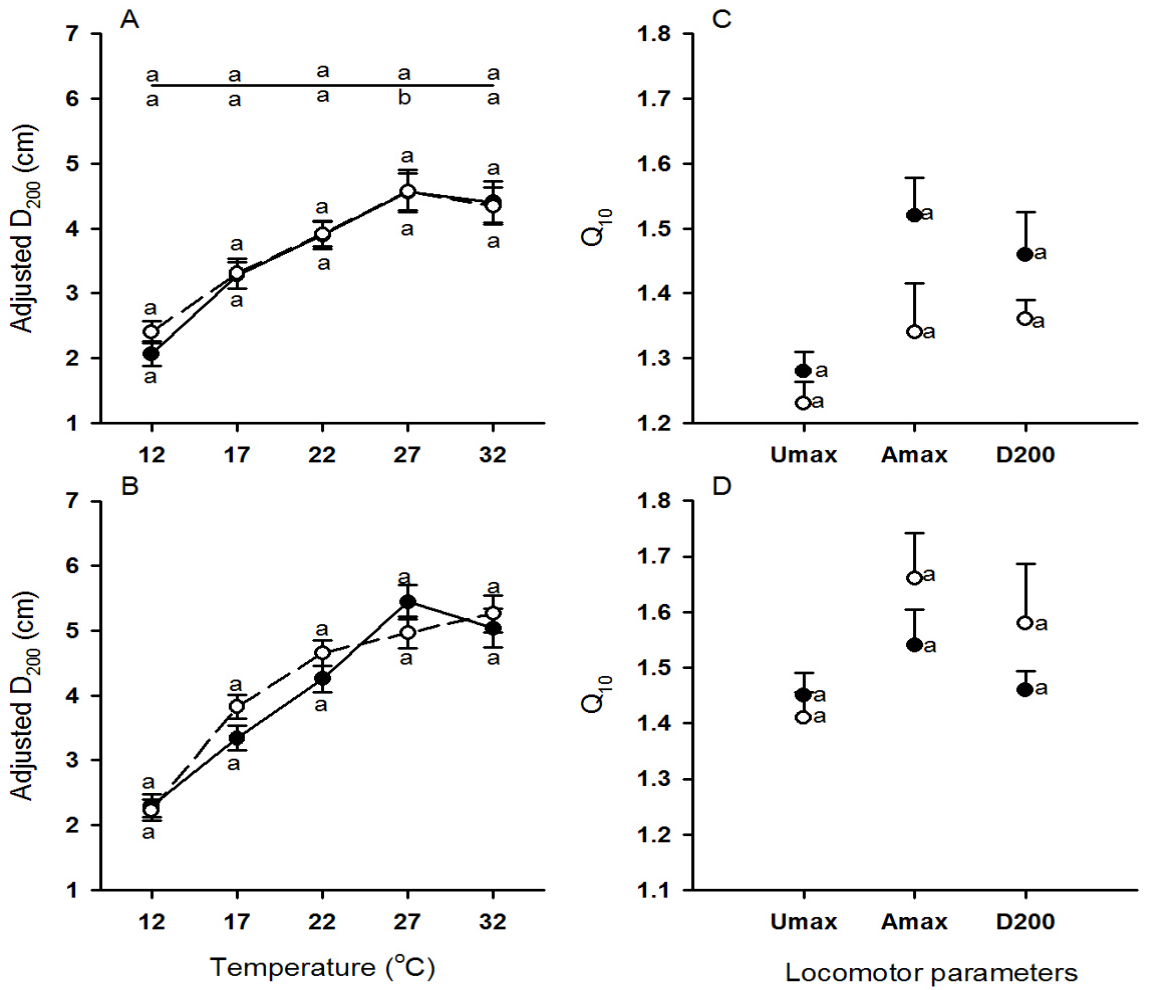

Figure 4. Distance moved within the initial $200 \mathrm{~ms}\left(\mathrm{D}_{200}\right)$ of burst swimming and thermal sensitivity represented by a $\mathrm{Q}_{10}$ value of three locomotion performances that were performed at test temperatures of $12-32^{\circ} \mathrm{C}$ by $B$ ufo bankorensis larvae acclimated at 15 and $22^{\circ} \mathrm{C}$ from Alishan in winter (०) and summer (•), respectively.

\section{Discussion and Conclusions}

The fact that the thermal acclimation ability of B. bankorensis larvae in burst swimming was lacking in the lowland population is consistent with the hypothesis addressed by Wilson and Franklin [27]. The differentiation of thermal acclimation ability in burst swimming between the altitudinal larvae of $B$. bankorensis supports the expectation that this ability is associated with the temperature niche-range of the environment. The lowland population, having a short breeding season and being exposed to a relatively stable thermal environment, has less thermal acclimation demand in larvae. The highland population should develop the acclimation ability in their larval burst swimming because the breeding season lasts all year.

Although the lowland larvae showed a slight increase in $\mathrm{D}_{200}$ at $12^{\circ} \mathrm{C}$ upon warm acclimation, the acclimation effect on $\mathrm{D}_{200}$ was not seen at any other test temperatures in any of the other swimming parameters. It is likely that the increase in $\mathrm{D}_{200}$ is a result of cold shock $\left(\right.$ at $\left.12^{\circ} \mathrm{C}\right)$ experienced by the warm acclimated larvae from the lowland, where they had never before experienced cold temperatures.

Locomotor-performance reaction to thermal acclimation was demonstrated by Renaud and Stevens [25] and Knowles and Weigl [38] for Rana pipiens and R. sylvatica, respectively. They found that locomotor performance was enhanced only at high temperatures upon warm acclimation and was not affected by cool acclimation at low temperatures. This supports our findings for B. bankorensis. A dissimilarity in the temperatures at which larvae exhibited thermal acclimation in burst swimming was shown by Wilson and Franklin [16] for Limnodynastes peronii larvae, which was found to enhance burst swimming at low temperatures upon cold acclimation. Moreover, Wilson et al. [20] showed that Xenopus laevis larvae not only increased their burst swimming at high temperatures upon warm acclimation, but also increased burst swimming at low temperatures upon cool acclimation. In addition, the jumping performance of adult $B$. woodhousii increased after both warm acclimation at high temperatures and cold acclimation at low temperatures [24]. However, several adult amphibians that lack thermal acclimation ability in their locomotor performance, e.g., B. americanus [25], B. boreas [39], Pseudacris 
triseriata [38], and L. tasmaniensis [40], have been found. Moreover, amphibians such as Eurycea guttolineata [22] and Pseudotriton ruber [21] exhibited enhanced swimming performance, but not running performance, at low temperatures after cold acclimation. The locomotor performance of the above species appeared in various patterns in response to thermal acclimation at different temperatures. This locomotor performance can be explained by the adaptive significance based on the phylogenetic framework.

There is controversy about the adaptive significance of thermal acclimation. Many researchers [25, 38, 41-44] have postulated hypotheses about the benefits of thermal acclimation of locomotor performance. Renaud and Stevens [25] showed increases in jumping distance at high temperature by thermal acclimation in Rana pipiens and R. sylvatica. Knowles and Weigl [38] suggested that the ability to escape from predators increases with rising seasonal temperature. However, Renaud and Stevens [25], in studying Bufo americanus, did not accept the above assumption. According to their research, the jumping performance was not sensitive to thermal acclimation. Although several studies rejected the beneficial acclimation hypothesis (BAH) [41-44], others think that these results were confounded by developmental plasticity, not just acclimation responses [45]. Nevertheless, acclimation changes cannot just be assumed to be beneficial, and the BAH must be rigorously tested.

The fact that the highland winter larvae of Bufo bankorensis swam faster than the lowland larvae at low temperatures $\left(12-17^{\circ} \mathrm{C}\right)$ supports our hypothesis that individuals from high altitudes (cool climates) perform better than individuals from low altitudes (warm climates) at low temperatures. Variations in locomotor performance consistent with the present study have been demonstrated in some closely related anuran species. A comparative study of swimming performance of anuran species across an altitudinal gradient in the Colombian Andes found that all high-elevation species were able to swim through a broad temperature range, whereas the low-elevation species showed little ability to move at low temperature [11]. The studies of John-Alder et al. [10] on the thermal dependence of jumping performance in 10 species of tree frogs showed that species breeding in cool seasons performed better at low temperatures than sympatric species breeding in warm seasons, and all high latitudinal species performed better than low latitudinal species at most test temperatures.

In contradistinction, some amphibian and reptilian species show very little within-species variations in thermal sensitivity of locomotor performance $[12,13]$. The only evidence demonstrating intraspecific variations in thermal sensitivity of locomotor performance was found in populations of the adult frog Limnodynastes peronii [8]. The populations from cooler climates generally performed better than those from warmer climates at low temperatures, and vice versa at high temperatures. Wilson [8] attributed the differences in jumping performance between populations of adult L. peronii to genetic differences, because the jumping performance could not be modified by long-term ( 8 weeks) temperature changes [27]. The difference between altitudinal populations of $B$. bankorensis was also probably the result of genetic differentiations or variations in thermal history during the early developmental stages, and probably not due to differences in thermal history during the later stages because both altitudinal larvae were acclimated at the same temperature in the laboratory for about a month and did not alter their swimming performance at low temperatures. Differences in embryonic and larval survival rates between the lowland and highland B. bankorensis suggested that the altitudinal populations were genetically differentiated, since the different altitudinal populations were reared at the same temperatures from fertilized eggs until metamorphosis [29].

The warm acclimated highland larvae of B. bankorensis performed better than the lowland larvae at high temperatures $\left(22 \sim 32^{\circ} \mathrm{C}\right)$. This finding did not support our hypothesis that lowland larvae exhibit better performance at higher temperature. Navas [11] found similar swimming performance at warm temperature for high-elevation and low-elevation anuran species in the Colombian Andes. Moreover, a similar pattern was also observed among latitudinal anuran species [10]. The highland B. bankorensis larvae selected for low temperatures apparently do not lose the potential to swim well at warm temperatures. The embryonic survival rate of the highland B. bankorensis was also higher than that of the lowland population at warm temperatures, as shown by Chang [29]. This may be beneficial when the highland larvae are washed downstream to warmer environments.

Furthermore, the thermal sensitivity $\left(\mathrm{Q}_{10}\right)$ of burst swimming in the highland B. bankorensis larvae was lower than that in the lowland population in the cool acclimation group. These findings are similar to those found by Navas [11] in other anuran species, which, in his opinion, may be important for maintaining relatively constant locomotor performance in the thermally variable environments at high 
altitudes. However, in the warm acclimation group, the thermal sensitivity of burst swimming in the highland larvae increases and is comparable to that in the lowland larvae. Nevertheless, the $Q_{10}$ values for the burst swimming parameters in B. bankorensis larvae are lower than those reported in other species of ectotherms $[1,14,16,18]$.

The highland $B$. bankorensis larvae collected in winter swam faster than the summer larvae at 12$22^{\circ} \mathrm{C}$. This finding supports the hypothesis that larvae from cool climates (winter) perform better at lower temperature than larvae from warm climates (summer). Because larvae from both seasons were acclimated at the same temperature for 28 days, the effect caused by differences in seasonal temperatures should have been eliminated. Furthermore, burst swimming in the larvae from both seasons was not affected by acclimation temperature at low temperatures. Therefore, the difference in burst swimming between seasonal larvae from the high altitude might be affected by factors other than environmental temperature. In addition, there might be some gene flow between seasonal populations, resulting in genetic variations for swimming performance between the summer and winter breeders of $B$. bankorensis.

In this study, variations in thermal sensitivity and the thermal acclimation ability of B. bankorensis larvae in burst swimming between the two populations, were elucidated. We further inferred that genetic variations in burst swimming performance between the two B. bankorensis larval populations might exist. Merakova and Gvozdik [46] found duel temperature fluctuations during embryogenesisinduced acclimation of swimming performance in larvae of the alpine newt Triturus alpestris. A study on the effect of embryogenic thermal history is, therefore, proposed. Moreover, comparable studies of species within and between phylogenetic lineages in the thermal sensitivity and acclimation of locomotor performance, are needed in order to determine their ecophysiological significance in a progressively changing thermal environment.

Acknowledgments. This paper is dedicated to the memory of Dr. Ping-Chun Lucy Hou, who passed away on January 18, 2012. Lucy invested all her energy in supporting the work of her students, and she was a great friend and colleague. Unfortunately, she did not live to see this paper published. Special thanks to Ms. Sharon Victor for her useful comments and for preparing the manuscript for publication.

\section{References}

1. A. F. Bennett, "Thermal dependence of locomotor capacity," American Journal of Physiology, vol. 259, no. 2, pp. R253-R258, 1990.

2. S. L. Chown and K. J. Gaston, "Macrophysiology for a changing world," Proceedings of the Royal Society BBiological Sciences, vol. 275, no. 1642, pp. 1469-1478, 2008.

3. R. B. Huey and R. D. Stevenson, "Integrating thermal physiology and ecology of ectotherms: Discussion of approaches," American Zoologist, vol. 19, no. 1, pp. 357-366, 1979.

4. J. G. Kingsolver and W. B. Watt, "Thermoregulatory strategies in Colias butterflies: Thermal stress and the limits to adaptation in temporally varying environments," American Naturalist, vol. 121, no. 1, pp. 32-55, 1983.

5. M. Lynch and W. Gabriel, "Environmental tolerance," American Naturalist, vol. 129, no. 2, pp. 283-303, 1987.

6. K. A. Christian and C. R. Tracy, "The effect of the thermal environment on the ability of hatchling Galapagos land iguanas to avoid predation during dispersal," Oecologia, vol. 49, no. 2, pp. 218-223, 1981.

7. T. A. Beddow, J. L. Vanleeuwen and I. A. Johnston, "Swimming kinematics of fast starts are altered by temperature acclimation in the marine fish Myoxocephalus scorpius," Journal of Experimental Biology, vol. 198, no. 1, pp. 203-208, 1995.

8. R. S. Wilson, "Geographic variation in thermal sensitivity of jumping performance in the frog Limnodynastes peronii," Journal of Experimental Biology, vol. 204, no. 24, pp. 4227-4236, 2001.

9. D. Bauwens, T. Garland, A. M. Castilla and R. Vandamme, "Evolution of sprint speed in lacertid lizards: Morphological, physiological, and behavioral covariation," Evolution, vol. 49, no. 5, pp. 848-863, 1995.

10. H. B. John-Alder, P. J. Morin and S. Lawler, "Thermal physiology, phenology, and distribution of tree frogs," American Naturalist, vol. 132, no. 4, pp. 506-520, 1988.

11. C. A. Navas, "Metabolic physiology, locomotor performance, and thermal niche breadth in neotropical anurans," Physiological Zoology, vol. 69, no. 6, pp. 1481-1501, 1996. 
12. P. E. Hertz, R. B. Huey and E. Nevo, "Homage to Santa Anita: Thermal sensitivity of sprint speed in agamid lizards," Evolution, vol. 37, no. 5, pp. 1075-1084, 1983.

13. H. B. John-Alder, M. C. Barnhart and A. F. Bennett, "Thermal sensitivity of swimming performance and muscle contraction in northern and southern populations of tree frogs (Hyla, Crucifer)," Journal of Experimental Biology, vol. 142, no. pp. 357-372, 1989.

14. T. P. Johnson and A. F. Bennett, "The thermal acclimation of burst escape performance in fish: An integrated study of molecular and cellular physiology and organismal performance," Journal of Experimental Biology, vol. 198, no. 10, pp. 2165-2175, 1995.

15. G. K. Temple and I. A. Johnston, "Testing hypotheses concerning the phenotypic plasticity of escape performance in fish of the family Cottidae," Journal of Experimental Biology, vol. 201, no. 3, pp. 317-331, 1998.

16. R. S. Wilson and C. E. Franklin, "Thermal acclimation of locomotor performance in tadpoles of the frog Limnodynastes peronii," Journal of Comparative Physiology B, vol. 169, no. 6, pp. 445-451, 1999.

17. D. Ball and I. A. Johnston, "Molecular mechanisms underlying the plasticity of muscle contractile properties with temperature acclimation in the marine fish Myoxocephalus scorpius," Journal of Experimental Biology, vol. 199, no. 6, pp. 1363-1373, 1996.

18. T. A. Beddow and I. A. Johnston, "Plasticity of muscle contractile properties following temperature acclimation in the marine fish Myoxocephalus scorpius," Journal of Experimental Biology, vol. 198, no. 1, pp. 193-201, 1995.

19. T. P. Johnson, A. F. Bennett and J. D. McLister, "Thermal dependence and acclimation of fast start locomotion and its physiological basis in rainbow trout (Oncorhynchus mykiss)," Physiological Zoology, vol. 69, no. 2, pp. 276-292, 1996.

20. R. S. Wilson, R. S. James and I. A. Johnston, "Thermal acclimation of locomotor performance in tadpoles and adults of the aquatic frog Xenopus laevis," Journal of Comparative Physiology B, vol. 170, no. 2, pp. 117-124, 2000.

21. G. A. Marvin, "Aquatic and terrestrial locomotor performance in a semiaquatic plethodontid salamander (Pseudotriton ruber): Influence of acute temperature, thermal acclimation, and body size," Copeia, vol., no. 4, pp. 704-713, 2003.

22. G. A. Marvin, "Effects of acute temperature and thermal acclimation on aquatic and terrestrial locomotor performance of the three-lined salamander, Eurycea guttolineata," Journal of Thermal Biology, vol. 28, no. 3, pp. 251-259, 2003.

23. M. E. Feder, "Effect of thermal acclimation on locomotor energetics and locomotor performance in a lungless salamander, Desmognathus ochrophaeus," Journal of Experimental Biology, vol. 121, no. pp. 271-283, 1986.

24. P. L. Londos and R. J. Brooks, "Effect of temperature acclimation on locomotory performance curves in the toad, Bufo woodhousii woodhousii," Copeia, vol., no. 1, pp. 26-32, 1988.

25. J. M. Renaud and E. D. Stevens, "The extent of long-term temperature compensation for jumping distance in the frog, Rana pipiens, and the toad, Bufo americanus," Canadian Journal of Zoology, vol. 61, no. 6, pp. 1284$1287,1983$.

26. L. C. Rome, "The effect of long-term exposure to different temperatures on the mechanical performance of frog muscle," Physiological Zoology, vol. 56, no. 1, pp. 33-40, 1983.

27. R. S. Wilson and C. E. Franklin, "Inability of adult Limnodynastes peronii (Amphibia : Anura) to thermally acclimate locomotor performance," Comparative Biochemistry and Physiology - Part A, vol. 127, no. 1, pp. 21-28, 2000 .

28. K. Y. Lue. Amphibians in Taiwan. Education Department of Taiwan Province, 109; 1990.

29. L. W. Chang. Heat tolerance and its plasticity in larval Bufo bankorensis from different altitutdes, Master's thesis. Taiwan: National Cheng Kung University; 2002.

30. M. Tejedo and R. Reques, "Plasticity in metamorphic traits of natterjack tadpoles: the interactive effects of density and pond duration," Oikos, vol. 71, no. pp. 295-304, 1994.

31. D. J. Stehouwer and P. B. Farel, "Development of hindlimb locomotor behavior in the frog," Developmental Psychobiology, vol. 17, no. 3, pp. 217-232, 1984.

32. R. S. Wilson and C. E. Franklin, "Effect of ontogenetic increases in body size on burst swimming performance in tadpoles of the striped marsh frog, Limnodynastes peronii," Physiological and Biochemical Zoology, vol. 73, no. 2, pp. 142-152, 2000.

33. D. A. Winter. Biomechanics and Motor Control of Human Movement. John Wiley and Sons; New York, 1990. 
34. A. Cappello, P. F. La Palombara and A. Leardini, "smoothing techniques," Internation Journal of Bio-Medical Computing, vol. 41, no. pp. 137-151, 1996.

35. J. H. Challis, "A procedure for the automatic determination of filter cutoff frequency for the processing of biomechanical data," Journal of Applied Biomechanics, vol. 15, no. 3, pp. 303-317, 1999.

36. C. F. Gerald and P. O. Wheatley. Applied Numerical Analysis. Addison-Wesley Publishing Company; California, 1994.

37. K. L. Gosner, " A simplified table for staging anuran embryos and larvae with notes on identification," Heerpetologica, vol. 16, no. pp. 183-190, 1960.

38. T. W. Knowles and P. D. Weigl, "Thermal dependence of anuran burst locomotor performance," Copeia, vol. 1990, no. pp. 796-802, 1990.

39. R. W. Putnam and A. F. Bennett, "Thermal dependence of behavioural performance of anuran amphibians," Animal Behaviour, vol. 29, no. pp. 502-509, 1981.

40. P. J. Whitehead, J. T. Puckridge, C. M. Leigh and R. S. Seymour, "Effect of temperature on jump performance of the frog Limnodynastes tasmaniensis," Physiological Zoology, vol. 62, no. 4, pp. 937-949, 1989.

41. A. A. Hoffmann, "Acclimation: Increasing survival at a cost," Trends in Ecology and Evolution, vol. 10, no. pp. $1-2,1995$.

42. R. B. Huey and D. A. Berrigan. Testing evolutionary hypotheses of acclimation. Cambridge University Press; 1996.

43. R. B. Huey, D. Berrigan, G. W. Gilchrist and J. C. Herron, "Testing the adaptive significance of acclimation: A strong inference approach," American Zoologist, vol. 39, no. pp. 323-336, 1999.

44. A. M. Leroi, A. F. Bennett and R. E. Lenski, "Temperature acclimation and competitive fitness: an experimental test of the beneficial acclimation assumption," Proceedings of the National Academy of Sciences of the United States of America, vol. 91, no. 5, pp. 1917-1921, 1994.

45. R. S. Wilson and C. E. Franklin, "Testing the beneficial acclimation hypothesis," Trends in Ecology and Evolution, vol. 17, no. pp. 66-70, 2002.

46. E. Merakova and L. Gvozdik, "Thermal acclimation of swimming performance in newt larvae: the influence of diel temperature fluctuations during embryogenesis," Functional Ecology, vol. 23, no. pp. 989-995, 2009. 